\title{
Mediterranean diet pyramid today. Science and cultural updates
}

\author{
Anna Bach-Faig ${ }^{1}$, Elliot M Berry ${ }^{2}$, Denis Lairon ${ }^{3}$, Joan Reguant ${ }^{1}$, Antonia Trichopoulou ${ }^{4}$, \\ Sandro Dernini ${ }^{5,6}$, F Xavier Medina ${ }^{7}$, Maurizio Battino ${ }^{8}$, Rekia Belahsen ${ }^{9}$, \\ Gemma Miranda ${ }^{1}$ and Lluís Serra-Majem ${ }^{1,10, *}$ on behalf of the Mediterranean Diet \\ Foundation Expert Group \\ ${ }^{1}$ Mediterranean Diet Foundation, Barcelona, Spain: ${ }^{2}$ Department of Human Nutrition and Metabolism, Braun \\ School of Public Health, Hebrew University-Hadassah Medical School, Jerusalem, Israel: ${ }^{3}$ Research Unit 1025 \\ Inserm/1260 Inra/"Human Nutrition and Lipids: Bioavailability, Metabolism and Regulations", Faculté de \\ Médecine, Université de la Méditerranée, Marseille, France: ${ }^{4}$ Hellenic Health Foundation, Athens, Greece: \\ ${ }^{5}$ Forum on Mediterranean Food Cultures, Rome, Italy: ${ }^{6}$ Interuniversity International Center for Mediterranean \\ Food Cultures Studies (CIISCAM), Sapienza University of Rome, Italy: ${ }^{7}$ Department of Food Systems, \\ Culture and Society, Faculty of Health Sciences, Universitat Oberta de Catalunya (UOC), Barcelona, Spain: \\ ${ }^{8}$ Department of Biochemistry, Università Politecnica delle Marche, Ancona, Italy: ${ }^{9}$ Department of Biology, \\ Faculty of Sciences, Chouaïb Doukkali University, El Jadida, Morocco: ${ }^{10}$ Department of Clinical Sciences, \\ University of Las Palmas de Gran Canaria, PO Box 550, 35080, Las Palmas de Gran Canaria, Spain
}

Submitted 13 May 2011: Accepted 7 September 2011

\begin{abstract}
Objective: To present the Mediterranean diet (MD) pyramid: a lifestyle for today. Design: A new graphic representation has been conceived as a simplified main frame to be adapted to the different nutritional and socio-economic contexts of the Mediterranean region. This review gathers updated recommendations considering the lifestyle, dietary, sociocultural, environmental and health challenges that the current Mediterranean populations are facing.

Setting and Subjects: Mediterranean region and its populations.

Results: Many innovations have arisen since previous graphical representations of the MD. First, the concept of composition of the 'main meals' is introduced to reinforce the plant-based core of the dietary pattern. Second, frugality and moderation is emphasised because of the major public health challenge of obesity. Third, qualitative cultural and lifestyle elements are taken into account, such as conviviality, culinary activities, physical activity and adequate rest, along with proportion and frequency recommendations of food consumption. These innovations are made without omitting other items associated with the production, selection, processing and consumption of foods, such as seasonality, biodiversity, and traditional, local and eco-friendly products.

Conclusions: Adopting a healthy lifestyle and preserving cultural elements should be considered in order to acquire all the benefits from the MD and preserve this cultural heritage. Considering the acknowledgment of the MD as an Intangible Cultural Heritage of Humanity by UNESCO (2010), and taking into account its contribution to health and general well-being, we hope to contribute to a much better adherence to this healthy dietary pattern and its way of life with this new graphic representation.
\end{abstract}

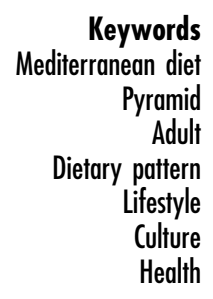

The traditional Mediterranean diet (MD) is the heritage of millennia of exchanges of people, cultures and foods of all countries around the Mediterranean basin. It has been the basis of food habits during the twentieth century in all countries of the region, originally based on Mediterranean agricultural and rural models. However, the traditional MD is now progressively eroding due to the widespread dissemination of the Western-type economy, urban and technology-driven culture, as well as the globalisation of food production and consumption, related to the homogenisation of food behaviours in the modern era.

Since the Seven Countries Study in the 1950s, we know which foods were more or less frequently consumed in the Mediterranean area ${ }^{(1)}$, a pattern followed mainly by poor rural societies ${ }^{(2)}$. This led to defining the MD as a dietary pattern rich in plant foods (cereals, fruits, vegetables, 
legumes, tree nuts, seeds and olives), with olive oil as the principal source of added fat, along with high to moderate intakes of fish and seafood, moderate consumption of eggs, poultry and dairy products (cheese and yoghurt), low consumption of red meat and a moderate intake of alcohol (mainly wine during meals).

The pioneer Seven Countries Study and numerous and increasing recent epidemiological studies have established the health benefits associated with the adherence to the Mediterranean diet pattern (MDP), mainly in relation to reducing the risk of developing the metabolic syndrome, type 2 diabetes, CVD and some neurodegenerative diseases and cancers ${ }^{(3-6)}$.

This healthy, traditional MDP has been popularised since 1995 using the world famous pyramid representation that graphically highlights the food groups to be consumed daily, weekly or less frequently ${ }^{(7)}$. In addition, in 1995, an index or score was introduced to evaluate the adherence to the MDP, allowing the study of its associated health effects $^{(8)}$. Within the scientific community, there is a consensus on what constitutes the traditional MDP, mentioned above, but issues have been raised about the need to update the present recommendations considering the new lifestyle, dietary, sociocultural, environmental and health challenges the current generations of different countries and sectors of the population are facing, especially low-income groups in which the prevalence of CVD has risen along with the shift from the traditional MD. The following issues, among others, arise and need to be addressed: (i) consumption of fresh, minimally processed, local and seasonal foodstuffs; (ii) the balance between energy-dense and nutrient-dense foods in relation to reduced energy expenditure and the obesity epidemic; (iii) availability, sustainability, accessibility and cost of recommended foods; (iv) adaptation to various geographical, socio-economic and cultural contexts; and (v) understanding the MD as an intangible space for creativity and intercultural dialogue and a common cultural heritage shared by all Mediterranean populations ${ }^{(9)}$.

The incorporation of food consumption as a basic area in Anthropology and Sociology after the 1930s - after the pioneering works of Audrey Richards and Margaret Mead has brought light to the study of nutrition understood also as a social and cultural process in permanent flux ${ }^{(10)}$. Food represents much more than a pure act of survival for human evolution; eating is a social and cultural phenomenon, while nutrition is a physiological and health issue ${ }^{(11)}$.

After the recognition of the $\mathrm{MD}$ as an Intangible Cultural Heritage of Humanity by UNESCO in $2010^{(12,13)}$, considering the worldwide interest in the MDP and taking as a framework all the mentioned aspects, scientists present a consensual renewed communication tool for the general public, health professionals and stakeholders. This is a new pyramid with which scientists hope to contribute to a much better adherence to this healthy dietary pattern and its way of life in the Mediterranean area and other countries in the near future.

\section{Consensus on a new pictorial representation of the Mediterranean diet pyramid}

The Mediterranean Diet Foundation together with the Forum on Mediterranean Food Cultures initiated the dialogue and process of gathering scientific opinion among international experts to develop a consensus position on a new revised MD pyramid representation (Fig. 1). The new revised MD and food lifestyle pyramid (as a schema) arises from the internal dialogues among scientific experts of the Mediterranean Diet Foundation's International Scientific Committee and further discussions from a meeting held in the framework of the III CIISCAM Conference 'The Mediterranean Diet today, a model of sustainable diet' in Parma (Italy; Fig. 1).

This pyramid results from the aforementioned scientific consensus among experts and is based upon the latest research in the field of nutrition and health, scientific evidence around the healthiness of the MD dietary pattern and its role in the prevention of many chronic diseases by large epidemiological studies published in hundreds of peer-reviewed scientific journal articles during recent decades $^{(3,4)}$.

The final design of the MD pyramid today (Fig. 2) and a brief complementary text for the general public (Fig. 3) have been developed by the gathered opinions of the Mediterranean Diet Foundation Expert Group that includes the Mediterranean Diet Foundation's International Scientific Committee expertise, the in situ discussions by a representative group of members that met within the Barcelona VIII International Congress on the Mediterranean diet (Fig. 1), and several other experts who provided support on the design, editing and translation to ten different languages (English, French, Italian, Spanish, Catalan, Basque, Galician, Greek, Portuguese and Arabic; see acknowledgements).

Thus, the main purpose of this initiative is to foster dialogue among scientists and experts in public health nutrition, food sciences, metabolism, anthropology, sociology, biology, agriculture and environmental and cultural heritage in order to obtain a common representation of the MDP in the Mediterranean area, meant for non-profit use and promotion without restrictions.

\section{The Mediterranean diet pyramid: a lifestyle for today}

The pyramid reflects the changing process that the MD is undergoing within the Mediterranean societies. This new graphic representation (Fig. 2) was conceived as a simplified main frame pyramid, to be adapted to the specific realities of different countries (e.g. portion sizes) and variations in the dietary pattern related to the various geographical, socio-economic and cultural contexts of the Mediterranean region. These guidelines (2010 edition) might be periodically updated according to new consensus and suggestions. 


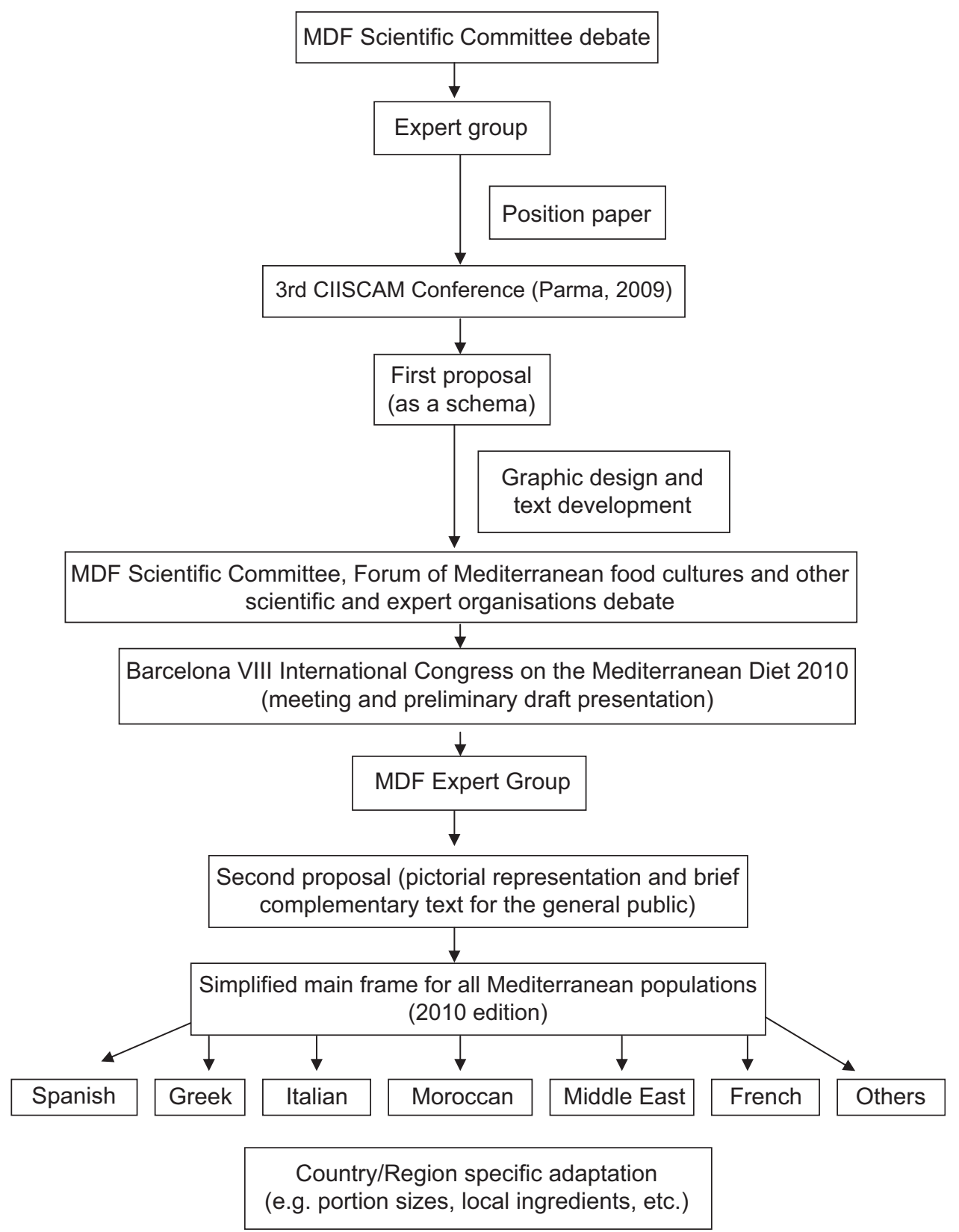

Fig. 1 The process in the development of the new modern Mediterranean diet pyramid (MDF, Mediterranean Diet Foundation; CIISCAM, International Inter-University Center for Mediterranean Food Culture Studies)

By expressing the goals in terms of foods and referring to a dietary pattern based on a cultural model, the new pyramid may contribute to a higher compliance among the general population. In order to preserve the Intangible Cultural Heritage, adapting the cultural specificity of each food practice to its socio-economic and environmental context is necessary. Thus, the pyramid is developed as a tool to help us adopt a healthier and sustainable lifestyle.

The recommendations target the healthy adult population (18-65 years old) and should be adapted to the special needs of children, pregnant women and those suffering from health conditions.

\section{Mediterranean diet pattern}

The new MD pyramid provides key elements for the selection of foods, both quantitative and qualitative, indicating the relative proportions and consumption frequency of servings of the main food groups that constitute the MDP. The pattern includes all food groups, and it is just a question of variety of food and culinary techniques, along with adequate frequencies and quantities in the daily diet that make it healthy or unhealthy. A wide variety of foods in the diet minimises the possibility of deficiencies of a particular nutrient. In fact, a higher adherence to the MDP has been associated with a better 
and respecting social beliefs

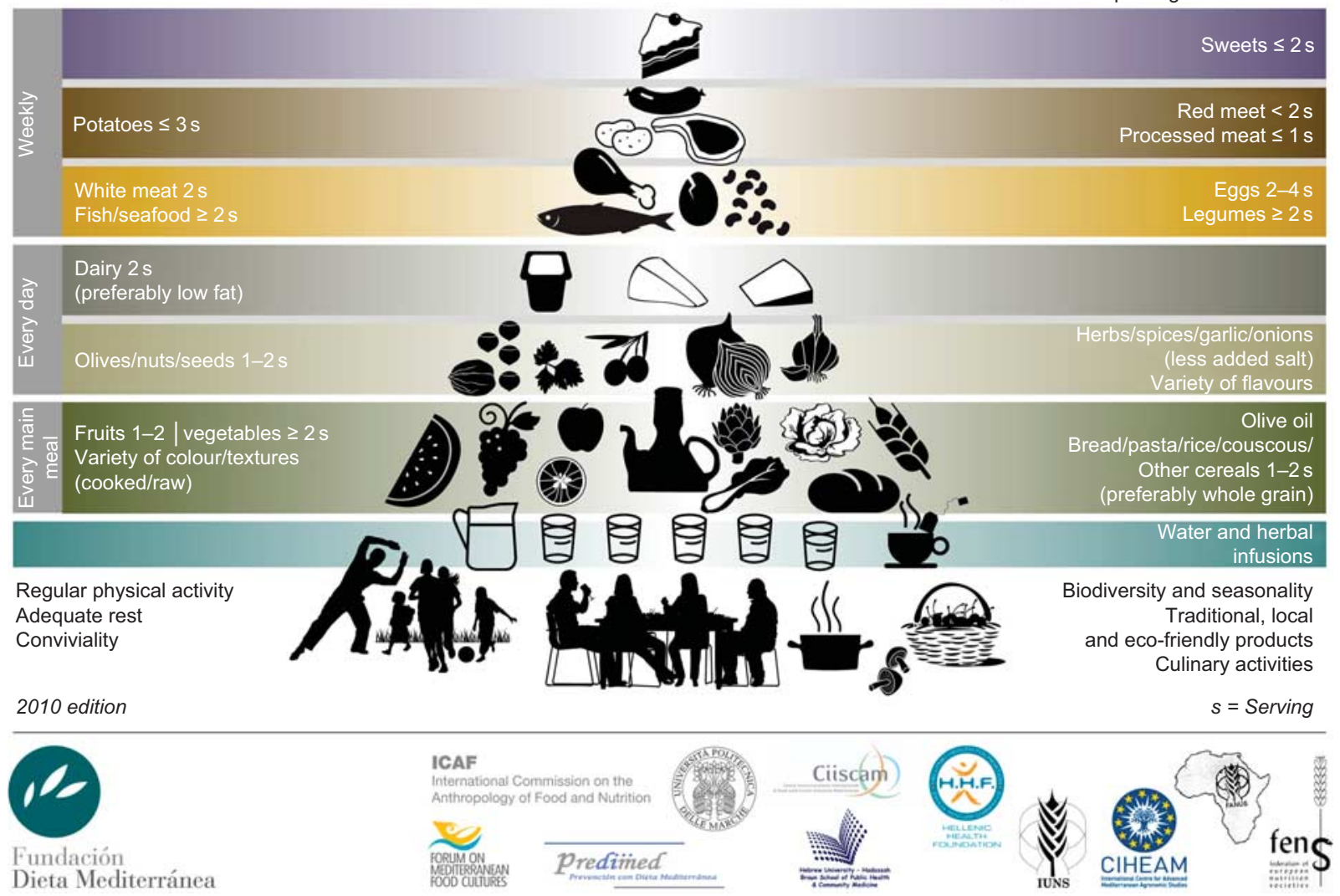

Fig. 2 (colour online) Mediterranean diet pyramid: a lifestyle for today

nutrient profile, with a lower prevalence of individuals showing inadequate intakes of micronutrients in comparison to other patterns such as the Western pattern ${ }^{(14)}$.

Plant-origin foods are situated at the base of the pyramid. They provide key nutrients, fibre and protective substances that contribute to general well-being, satiety and the maintenance of a balanced diet, and thus should be consumed in high proportions and frequency. This MD core, based on plant-origin foods, is responsible for the prevention of many chronic diseases and for weight control $^{(4,15)}$

The graphic representation follows the previous pattern: at the base, food items that should sustain the diet and provide the highest energy intake, and at the upper levels, foods to be eaten in moderate amounts such as those of animal origin and/or rich in sugars and fats that should be eaten in moderation and some of them left for special occasions. Meals have an essential role in the $\mathrm{MD}^{(16)}$, and thus the importance of the meal and its composition is emphasized in the new representation. A balanced composition of the main meals should include fruits, vegetables and cereals, complemented in a lower contribution to daily energy intake with other plant foods, dairy products and protein sources.
The pyramid establishes dietary daily, weekly and occasional guidelines in order to follow a healthy and balanced diet.

\section{Every day}

- Main meals should contain three basic elements, which can also be found throughout the day:

- Cereals: one or two servings per meal in the form of bread, pasta, rice, couscous and others. Preferably whole grain, since processing normally removes fibre and some valuable nutrients ( $\mathrm{Mg}, \mathrm{Fe}$, vitamins, etc. $)^{(17)}$.

- Vegetables: two or more servings per meal. In order to ensure vitamin and mineral daily intakes, at least one of the servings should be consumed raw (one meal/d) ${ }^{(18)}$.

- Fruit: one or two servings per meal, as the most frequently chosen dessert. The concept of 'variety in colours and textures' is highlighted, in the case of fruit and vegetables, in order to ensure a wide variety of antioxidants and protective compounds ${ }^{(19)}$.

- A daily intake of 1.5-2 1 of water (equivalent to six to eight glasses) should be guaranteed. Proper hydration is essential to maintaining the corporal water equilibrium, 


\section{The Mediterranean diet pyramid has adapted to the new way of life}

\section{The new model takes into account qualitative and quantitative elements for the selection of foods}

The traditional Mediterranean diet (MD) pyramid has evolved to adopt the new way of life. As an initiative of the Mediterranean Diet Foundation and with the collaboration of numerous international entities, a wide range of experts in nutrition, anthropology, sociology and agriculture have reached a consensus in a new richer design with the incorporation of qualitative elements. The new pyramid follows the previous pattern: at the base, foods that should sustain the diet, and at theupper levels, foods to be eaten in moderate amounts. Moreover, social and cultural elements characteristic of the Mediterranean way of life are incorporated in the graphic design. So, it is not just about prioritising some food groups from others, but also paying attention to the way of selecting, cooking and eating. It also reflects the composition and number of servings per meals.

The Mediterranean diet health benefits and protective effect against chronic diseases have been well established by the scientific community. This new pyramid includes all the food groups; it is in the proportions and the frequencies that relies a healthy or unhealthy diet. This food consumption pattern is addressed to a healthy adult population and should be adapted to the specific needs of children, pregnant women and other health conditions.

Plant-based foods are situated at the base of the pyramid. They provide key nutrients and protective substances that contribute to the general well-being and contribute to maintain a balanced diet, therefore, should be consumed in high proportions and frequency. Foods situated in the upper levels such as from animal origin, rich in sugars and in fats should be eaten in moderation and left for special occasions.

The pyramid establishes dietary daily, weekly and occasional guidelines in order to follow a healthy and balanced diet.

\section{Every day:}

The three main meals should contain three basic elements, which can also be found throughout the day:

- Cereals. One or two servings per meal in the form of bread, pasta, rice, couscous and others. Preferably whole grain, since some valuable nutrients (magnesium, phosphorus, etc.) and fibre can be lost during processing.

- Vegetables. Present at lunch and dinner; or more than two servings per meal, at least one of the serving should be raw. A variety of colours and textures provide a diversity of antioxidants and protective compounds.

- Fruit. One or two servings per meal. Should be chosen as the most frequent dessert.

- A daily intake of 1.5-2.0 liter of water should be guarantied. A good hydration is essential to maintain the corporal water equilibrium, although needs may vary among people because of age, physical activity, personal circumstances and weather conditions. As well as water, non-sugar rich herbal infusions and broths (with low fat and salt content) may complete the requirements.

- Dairy products. Prefer it in the form of low fat yoghurt, cheese and other fermented dairy products. They contribute to bone health, but can also be an important source of saturated fat.

- Olive oil is located at the centre of the pyramid; should be the principal source of dietary lipids because of its high nutritional quality (especially extra virgin). Its unique composition gives it a high resistance to cooking temperatures and should be used for cooking as well as dressings (one tablespoon per person).

- Spices, herbs, garlic and onions are a good way to introduce a variety of flavours and palatability to dishes and contribute to the reduction of salt addition. Olives, nuts and seeds are good sources of healthy lipids, proteins, vitamins, minerals and fibre. A reasonable consumption of olives, nuts and seeds (such as a handful) make for a healthy snack choice.

- $\quad$ Respecting religious and social beliefs, a moderate consumption of wine and other fermented beverages (one glass per day for women and two glasses per day for men, as a generic reference) during meals is recommended.

\section{Weekly:}

A variety of plant and animal origin proteins should be consumed. Mediterranean traditional dishes do not usually have animal origin protein foods as the main ingredient but as a tasty source.

- $\quad$ Fish (two or more servings), white meat (two servings) and eggs (two to four servings) are good sources of animal protein. Fish and shellfish are also a good source of healthy proteins and lipids.

- Consumption of red meat (less than two servings, preferably lean cuts) and processed meats (less than one serving) should be in smaller quantity and frequency.

Fig. 3 (colour online) The Mediterranean diet pyramid's brief complementary text for the general public 
- The combination of legumes (more than two servings) and cereals are a healthy protein and lipid source. Potatoes are also included in this group, as they are a part of many traditional recipes with meat and fish (three or less servings per week, preferably fresh potatoes).

\section{Occasionally:}

In the vertex of the pyramid are represented the sugary and unhealthy fats rich foods (the sweets). Sugar, candies, pastries and beverages such as sweetened fruit juices and soft drinks, should be consumed in small amounts and left for special occasions.

Together with the proportion and frequency recommendations of consumption, the incorporation of lifestyle and cultural elements is one of the innovations of the pyramid. Adopting a healthy lifestyle and preserving the cultural elements should also be considered in order to acquire all the benefits from the Mediterranean diet. These elements are:

Moderation: Portion sizes should be based on frugality, adapting energy needs to urban and modern sedentary lifestyles.

Socialisation: The aspect of conviviality is important for the social and cultural value of the meal, beyond nutritional aspects. Cooking, sitting around the table and sharing food in company of family and friends is a social support and gives a sense of community.

Cooking: Make cooking an important activity taking the proper time and space. Cooking can be relaxing, fun and can be done with family, friends and the loved ones.

Seasonality, biodiversity, eco-friendliness, traditional and local food products are presented at the bottom of the pyramid to highlight how the new revised modern Mediterranean diet is compatible with the development of a sustainable diet model for the present and future Mediterranean generations. The preference for seasonal, fresh and minimally processed foods maximises the content of protective nutrients and substances in the diet.

Activity: Regular practice of moderate physical activity (at least 30 min throughout the day) as a basic complement to the diet for balancing energy intake, for healthy body weight maintenance and for many other health benefits. Walking, taking the stairs $v$. the lift, housework, etc., are simple and easy ways of doing exercise. Practising leisure activities outdoors and preferably with others makes it more enjoyable and strengthens the sense of community.

Rest: Resting is also part of a healthy and balanced lifestyle.

This pyramid is the result of an international consensus and is based on the latest scientific evidence on nutrition and health published in hundreds of scientific articles in the last decades. It contributes to the harmonisation of educational tools used in the promotion of the Mediterranean diet and responds to the need for a common framework among the Mediterranean area; to be adapted to the specific realities of each country and region. The use and promotion of this pyramid is recommended without any restrictions and has been translated and is available in English, Spanish, Catalan, Galician, Basque, French, Arabic, Italian, Portuguese and Greek.

The supporting entities of the new design of the Mediterranean diet pyramid are:

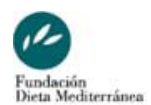

Fundación Dieta Mediterránea

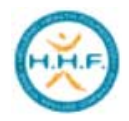

Hellenic Health Foundation

ICAF

International Commission on the

International Commission on the Anthropology of Food and Nutrition

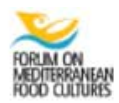

Forum on Mediterranean Food Cultures

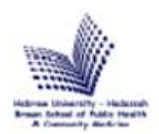

Hebrew University

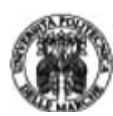

Università Politecnica delle Marche 


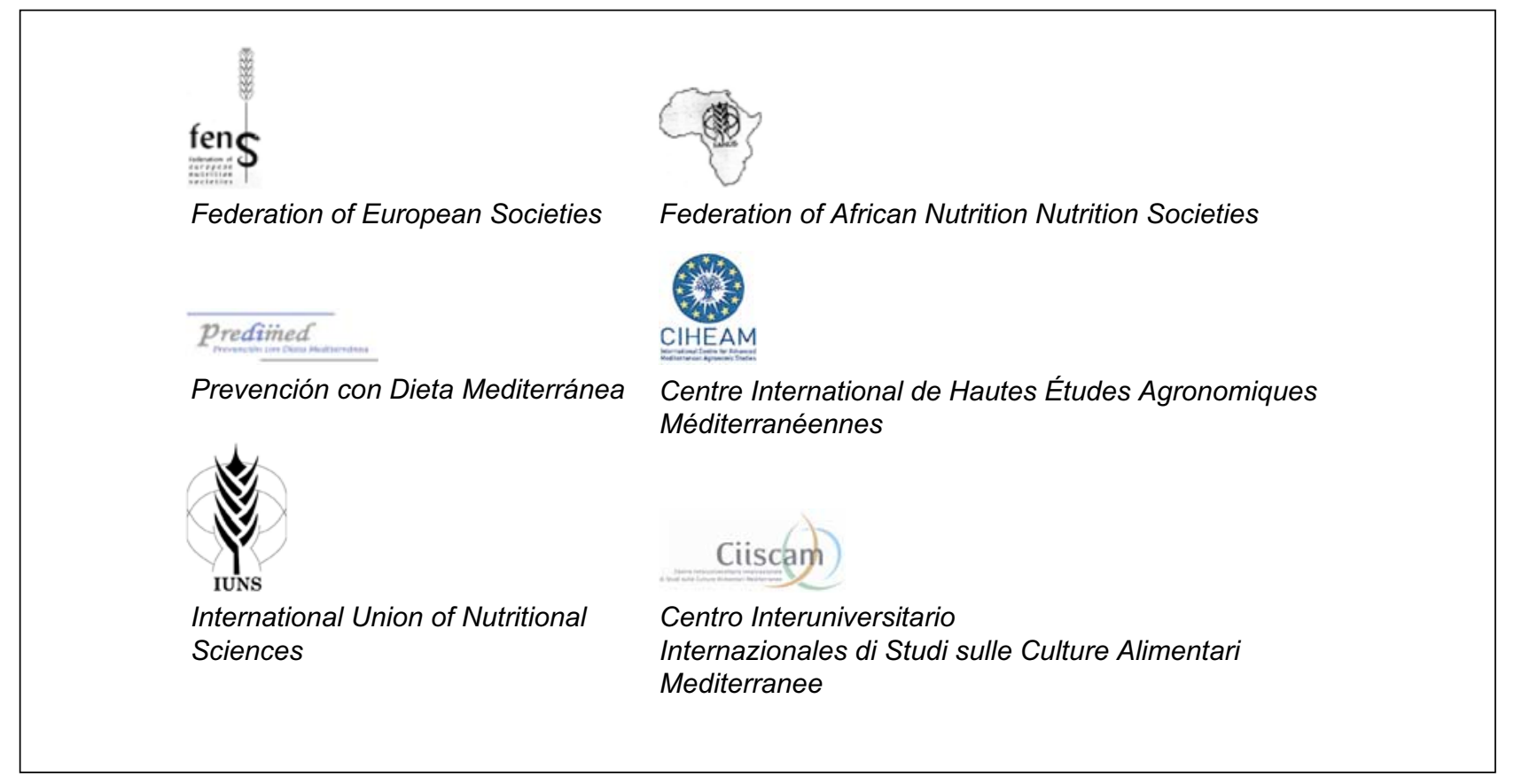

Fig. 3 (Continued)

although needs may vary among people due to age, physical activity, personal circumstances and weather conditions. It should be consumed freely, bottled or from the tap, when hygienic circumstances allow it. In addition to water, sugar-free herbal infusions and tea, and low-sodium and low-fat broths may help to complete the requirements.

- Dairy products should be present in moderate amounts (two servings per day), with a preference for low-fat dairy, traditionally in the form of yoghurt, cheese and other fermented dairy products. Although their richness in $\mathrm{Ca}$ is important for bone and heart health, dairy products can be a major source of saturated fat ${ }^{(20)}$.

- Olive oil is located at the centre of the pyramid; it should be the principal source of dietary lipids because of its high nutritional quality (especially extra virgin olive oil). Its unique composition gives it a high resistance to elevated temperatures, and it is recommended for both cooking ${ }^{(21)}$ and dressings. Olive oil has been reported to be inversely associated with some cancers and is known to positively affect blood lipids and cardiovascular systems ${ }^{(22-26)}$. This may be related to its high content of monounsaturated oleic acids and abundance of antioxidant compounds, which are primarily present in virgin olive oil ${ }^{(27)}$. Traditionally, vegetables and other plant foods are cooked with olive oil, thus amplifying their nutritional value.

- Olives, nuts and seeds are good sources of healthy lipids, proteins, vitamins, minerals and fibre ${ }^{(28)}$. A reasonable consumption of olives, nuts and seeds (such as a handful) make for a healthy snack choice.
- Spices, herbs, garlic and onions are a good way to introduce a variety of flavours and palatability to dishes and allow for a reduction in salt use, as salt is one of the main contributing factors to the development of hypertension among predisposed individuals ${ }^{(29)}$. Herbs and spices are good sources of micronutrients and antioxidant compounds and also contribute to the regional identities of Mediterranean dishes.

- Respecting religious and social beliefs, a moderate consumption of wine and other fermented beverages during meals (one glass per day for women and two glasses per day for men, as a generic reference) is present in the $\mathrm{MDP}^{(30-32)}$.

\section{Weekly}

Consumption of a variety of plant- and animal-origin proteins is recommended. Traditional Mediterranean dishes do not usually have animal-origin protein foods as the main ingredient but rather as a source of flavour.

- Fish and shellfish (two or more servings), white meat (two servings) and eggs (two to four servings) are good sources of animal protein. Fish, white meat (poultry, turkey, rabbit, etc.) and eggs provide high-quality protein. Fish and shellfish are a good source of healthy protein and lipids. Varied consumption (of oily fish, lean fish and shellfish) is recommended. Fish (especially those high in lipids) and shellfish consumption has been reported to reduce the risk of CHD and they have anti-inflammatory properties due to their content of long chain $n$-3 PUFA ${ }^{(33,34)}$. White meat is also a good 
source of lean protein without the high levels of saturated fat found in some red meat cuts. Egg consumption, including those used in cooking as well as baking, should be between two and four times per week.

- Consumption of red meat (less than two servings, preferably lean cuts) and processed meats (less than one serving) should be small in both quantity and frequency as the intake of such meats has been consistently associated with some chronic diseases (cancers and CHD) ${ }^{(35,36)}$.

- The combination of legumes (more than two servings) and cereals is a healthy plant protein and lipid source that should be considered as a meat alternative ${ }^{(37,38)}$.

- Potatoes are also included on the weekly level (three or fewer servings per week, preferably fresh), as they are a part of many traditional recipes with meat and fish. They should be consumed in moderation ${ }^{(39)}$ as they have a high glycaemic index ${ }^{(40)}$ and are most commonly prepared fried.

\section{Occasionally}

In the top vertex of the pyramid are the foods rich in sugars and unhealthy fats (sweets). Sugar, candies, pastries and beverages such as sweetened fruit juices and soft drinks should be consumed in small amounts and set aside for special occasions. These foods are energy dense and are likely to contribute to weight gain ${ }^{(39)}$. Simple sugars, which are abundant in sweets, pastries, fruit juices and soft drinks, have been associated with an increased occurrence of tooth decay ${ }^{(36)}$.

\section{Cultural and lifestyle elements}

Along with recommendations regarding the proportion and frequency of food consumption, the incorporation of cultural and lifestyle elements is one of the innovations of the pyramid. Adopting a healthy lifestyle and preserving cultural elements should also be considered in order to acquire all the benefits from the MD and to preserve this cultural heritage. These concepts represented outside of the pyramid, but at its base, are as follows.

\section{Moderation}

Serving sizes should be based on frugality and moderation, to adapt the urban and modern lifestyles to energy needs. This aspect is emphasised due to the major public health challenge of obesity. The portion sizes of the foods represented at the bottom should be larger and consumed frequently as they provide satiety along with moderate amounts of energy, and those foods at the upper levels should be consumed in smaller amounts and less frequently due to their high fat and simple sugar contents. Serving sizes should reflect autochthonous peculiarities and local habits, thus adapting to the specific realities of each country and region.

\section{Socialisation}

The conviviality aspect is important for the social and cultural value of the meal beyond nutritional aspects. In this sense, several factors related to food (understood as a social fact) must be kept in mind, such as culinary activities, knowledge transmitted from generation to generation and time devoted to meals related to the daily pace of life. All these aspects contribute to generating or strengthening sociability, communication and the identity of communities. Sharing food in the company of family and friends around the table represents social support and a sense of community ${ }^{(41)}$. The pleasure associated with the conviviality of meals may positively affect food behaviours, and in return, health status ${ }^{(42)}$.

\section{Culinary activities}

The development of culinary activities such as cooking, making crafts, the organisation of domestic space and other techniques associated with food is basic for the social reproduction of the identity of each particular culture $^{(10)}$. Thus, devoting enough time and space for such culinary activities is stressed, giving account to their role in everyday meals, celebrations and religious festivals in every culture.

\section{Physical activity}

Regular practice of moderate physical activity (at least $30 \mathrm{~min}$ throughout the day) serves as a basic complement to the diet by balancing energy intake, maintaining healthy body weight and providing many other health benefits ${ }^{(36)}$. Physical activity not only involves sports such as football, dancing, jogging, cycling, etc. but also walking, taking the stairs $v$. the lift, housework, gardening, etc. Practising leisure activities outdoors $^{(43)}$, and preferably with others, makes them more enjoyable and strengthens the sense of community.

\section{Adequate rest}

Resting during the day (nap) as well as adequate night sleep is also part of a healthy and balanced lifestyle. Scientific evidence has shown that a short rest after eating is a healthy and traditional Mediterranean habit that helps promote a balanced lifestyle ${ }^{(44)}$. An after-meal nap is an increasingly widespread habit in Mediterranean countries and throughout Europe.

\section{Seasonality}

The preference for seasonal, fresh and minimally processed foods may in most cases maximise the content of protective nutrients and substances in the diet. Currently and due to the modern lifestyle, the consumption of fresh foods is being substituted by other processed foods. However, progress in modern technology minimises nutrient loss and offers healthy alternatives ${ }^{(45)}$. Especially in the case of fresh products, several factors influence their nutritional value: the growing methods used, the specific variety chosen, ripeness when harvested, postharvest handling, storage, extent and type of processing, and the distance transported ${ }^{(46)}$. Thus, all the decisions and practices along the food system - from seed to table affect the nutrient content of foods. 
Traditional, local, eco-friendly and biodiverse products Taking into account the traditional, local, eco-friendly and biodiverse products whenever possible contributes to the preservation of Mediterranean landscapes and sea. The MD should be understood not only as a set of foods but also a cultural model incorporating the whole food chain: the way foods are selected, produced, processed and distributed to the consumers ${ }^{(13,47)}$. Moreover, the MD, as a plant-centred dietary pattern, further contributes to the preservation of the environment, as it implies a reduction in animal consumption and therefore production compared to Western patterns and, consequently, lowered demands on soil, water and energy resources ${ }^{(48,49)}$. All these items express the sustainable character of the MD in an increasingly globalised world ${ }^{(47,50,51)}$.

The MD is an example of a sustainable pattern in which agricultural biodiversity plays an important role ${ }^{(47,51)}$. The variety both among and within species contributes to differences in appearance and taste, as well as micronutrient and phytochemical content ${ }^{(46)}$. However, when making varietal decisions, durability (for instance, to withstand long-distance transport) is sometimes being prioritised over taste and nutritional quality ${ }^{(52)}$. The large number of endemic species and landscape diversification (cultivated areas, grassland or forest and land use changes over time) that contribute to the biodiversity of the territories bordering the Mediterranean make this area a hot spot of global diversity ${ }^{(53)}$. In this sense, agricultural biodiversity provides food variety of plant and animal food products from wild and domesticated sources ${ }^{(54)}$ that foster the nutritional guidelines ${ }^{(55)}$.

The consumption of local and eco-friendly foods has been associated with health and environmental preservation in several ways ${ }^{(50)}$. First, although there is still no unanimous international consensus on the differences in nutrient content between eco-friendly and conventional products ${ }^{(56)}$, some literature surveys of nutritional and sanitary aspects of eco-friendly (organic) foods ${ }^{(57,58)}$ have reported some higher nutrient contents and marginal pesticide residue contaminations. Second, locally grown and harvested foods are normally given more time to ripen. Third, local food products normally have less distance to travel, thus promoting energy saving and reducing pollution, having a lower contribution to climate change and greenhouse gas emissions if compared to long-travelling food products ${ }^{(59)}$. Moreover, by buying local foods, farmers are encouraged to diversify their crops and decrease their vulnerability to pests ${ }^{(50)}$. Finally, the consumption of local foods contributes to improving local economies ${ }^{(60)}$.

Traditional knowledge and practices developed through daily observation, interaction within rural communities, transfer production, procurement and consumption techniques and activities are locally transmitted from generation to generation ${ }^{(11)}$. All those elements ensure positive, responsible, sustainable and healthy behaviours ${ }^{(48,50,55)}$ while reproducing the Intangible Cultural Heritage of the Mediterranean Diet ${ }^{(13)}$. The modernisation process, including sociocultural changes and new technologies, has transformed food production and threatens sustainable orders of life, such as local foodstuffs and environmental biodiversity. Thus, countries, communities and cultures that maintain their own traditional food systems are better able to conserve local food specialities with a corresponding diversity of crop varieties and animal breeds ${ }^{(50,61)}$.

\section{Conclusions}

This pyramid is the result of an international consensus and is based on the latest scientific evidence on nutrition and health published in hundreds of scientific articles in recent decades. It contributes to the harmonisation of educational tools used in the promotion of the MD and responds to the need for a common framework in the Mediterranean area, to be adapted to each country's and region's specific realities. The use and promotion of this pyramid is recommended without any restrictions, and the material is available in English, Spanish, Catalan, Galician, Basque, French, Arabic, Italian, Portuguese and Greek.

The 'Mediterranean diet pyramid: a lifestyle for today' summarises and updates the traditional MD of those areas of the Mediterranean basin that have evolved with modernisation. It is a shared and dynamic cultural heritage that was recognised by UNESCO in 2010. Taking into account its contribution to health and general wellbeing, we hope to contribute to a much better adherence to this healthy dietary pattern and its way of life with this new graphic representation.

\section{Acknowledgements}

The present study was supported by the Mediterranean Diet Foundation, the Spanish Government (Ministerio de Medio Ambiente y Medio Rural y Marino), Interuniversity International Center for Mediterranean Food Cultures Studies (CIISCAM), Fundación Patrimonio Comunal Olivarero, Università Degli Studi di Parma, Istituto Nazionale di Riverca per gli Alimenti e la Nutrizione (INRAN). The authors have no conflict of interest to declare. The authors contributed as follows: A.B.F., E.M.B., D.L., J.R., A.T., S.D., X.F.M., M.B., R.B. and L.S.M.: conceived and designed the study and revised the manuscript; A.B.F.: conducted the literature review and wrote the manuscript; G.M.: further developed some concepts, identified additional references and edited the subsequent drafts of the manuscript; L.S.M.: coordinated the study. All authors have seen and approved the content and contributed to the work. The Mediterranean Diet Foundation Expert Group contributed intellectually and scientifically to the project. The authors thank the members of the Mediterranean Diet Foundation Expert Group (Lluís Serra-Majem (Chair, Las Palmas de Gran 
Canaria and Barcelona, Spain), Joan Reguant (Andorra la Vella, Andorra), Anna Bach-Faig (Barcelona, Spain), Antonia Trichopoulou (Athens, Greece), Denis Lairon (Marseille, France), Elliot Berry (Jerusalem, Israel), Sandro Dernini (Rome, Italy), Francesc Xavier Medina (Barcelona, Spain), Maurizio Battino (Ancona, Italy), Javier Aranceta (Bilbao, Spain), Tola Atinmo (Ibadan, Nigeria), Juan Miguel Barros (Santiago de Compostela, Spain), Rekia Belahsen (El Jadida, Morocco), Sabah Benjelloun (Rabat, Morocco), Isabel Bertomeu-Galindo (Barcelona, Spain), Barbara Burlingame (Rome, Italy), Marc Caballero-Bartolí (Barcelona, Spain), Carmen Clapés-Badrinas (Barcelona, Spain), Sandrine Couto (Porto, Portugal), Ibrahim Elmadfa (Vienna, Austria), Ramón Estruch (Barcelona, Spain), Amanda Faig (Toronto, Canada), Flaminio Fidanza (Perugia, Italy), Silvia Franceschi (Lyon, France), Joseph Hautvast (Wageningen, Holland), Elisabeth Helsing (Oslo, Norway), Diana JuliàLlobet (Barcelona, Spain), Carlo La Vecchia (Milano, Italy), Aicha Lemtouni (Rabat, Morocco), Abel Mariné (Barcelona, Spain), Miguel A. Martínez-González (Pamplona, Spain), Gemma Miranda (Barcelona, Spain), Ridha Mokni (Tunis, Tunisia), Francisco Mombiela (País, France), Idoia Noain (Ordizia, Spain), Biel Obrador (Barcelona, Spain), Gülden Pekcan (Ankara, Turkey), Suzanne Piscopo (Msida, Malta), Blanca Raidó-Quintana (Barcelona, Spain), Emilio Ros (Barcelona, Spain), Sara Sáez-Almendros (Barcelona, Spain), Jordi Salas-Salvadó (Reus, Spain), Francisco Sensat (Barcelona, Spain), Dimitrios Trichopoulos (Boston, United States), Josep Antoni Tur (Palma de Mallorca, Spain), Maria Daniel Vaz da Almeida (Porto, Portugal) and Walter C. Willett (Boston, MA, USA)) and the 2009 CIISCAM Conference experts (Marie Joseph Amiot-Carlin (Marseille, France), Anna Bach-Faig (Barcelona, Spain), Rekia Belahsen (El Jadida, Morocco), Alfonsina Bellio (Cosenza, Italy), Elliot Berry (Jerusalem, Israel), Barbara Burlingame (Rome, Italy), Carlo Cannella (Rome, Italy), Roberto Capone (Bari, Italy), Davide Cassi (Parma, Italy), Sandro Dernini (Rome, Italy), Lorenzo M. Donini (Rome, Italy), Cosimo Lacirignola (Bari, Italy), Denis Lairon (Marseille, France), Giuseppe Maiani (Rome, Italy), Mario Mancini (Naples, Italy), Francesc Xavier Medina (Barcelona, Spain), Nicolo Merendino (Viterbo, Italy), Martine Padilla (Montpellier, France), Stefano Padulosi (Rome, Italy), Lluís Serra-Majem (Las Palmas de Gran Canaria, Spain), Antonia Trichopoulou (Athens, Greece)) for their contributions.

\section{References}

1. Keys A, Menotti A, Karvonen MJ et al. (1986) The diet and 15-year death rate in the Seven Countries Study. Am J Epidemiol 124, 903-915.

2. Trichopoulou A (2004) Traditional Mediterranean diet and longevity in the elderly: a review. Public Health Nutr 7, 943-947.

3. Serra-Majem L, Roman B \& Estruch R (2006) Scientific evidence of interventions using the Mediterranean diet: a systematic review. Nutr Rev 64, Suppl. 1, S27-S47.
4. Sofi F, Cesari F, Abbate R et al. (2008) Adherence to Mediterranean diet and health status: meta-analysis. BMJ 337, a1344.

5. Benetou V, Trichopoulou A, Orfanos P et al. (2008) Greek EPIC cohort. Conformity to traditional Mediterranean diet and cancer incidence: the Greek EPIC cohort. BrJ Cancer 99, 191-195.

6. Meydani M (2005) A Mediterranean-style diet and metabolic syndrome. Nutr Rev 63, 312-314.

7. Willett WC, Sacks F, Trichopoulou A et al. (1995) Mediterranean diet pyramid: a cultural model for healthy eating. Am J Clin Nutr 61, Suppl. 6, 1402S-1406S.

8. Trichopoulou A, Ocurrís-Blazos A, Wahlqvist ML et al. (1995) Diet and overall survival in elderly people. BMJ 311, 1457-1460.

9. Reguant-Aleix J, Arbore R, Bach-Faig A et al. (2009) Mediterranean diet: an intangible cultural heritage. Public Health Nutr 12, 1591-1594.

10. Heine P (1994) Middle Eastern food. The anthropologists' perspective. In La alimentación en las culturas islámicas, pp. 159-167 [M Marín and D Saines, editors]. Madrid: Agencia Española de Cooperación Internacional.

11. Contreras J (1993) Antropología de la alimentación, p. 9. Madrid: Ediciones de la Universidad Complutense.

12. UNESCO (2003) Convention for the Safeguarding of the Intangible Cultural Heritage. http://www.unesco.org/ culture/ich/doc/src/01852-EN-pdf (accessed April 2011).

13. UNESCO (2010) Representative List of the Intangible Cultural Heritage of Humanity. http://www.unesco.org/ culture/ich/en/RL/00394 (accessed April 2011).

14. Serra-Majem L, Bes-Rastrollo $\mathrm{M}$, Román-Viñas $\mathrm{B}$ et al. (2009) Dietary patterns and nutritional adequacy in a Mediterranean country. Br J Nutr 101, Suppl. 2, S21-S28.

15. Buckland G, Bach-Faig A \& Serra-Majem L (2008) Obesity and the Mediterranean diet: a systematic review of observational and intervention studies. Obes Rev 9, 582-593.

16. Centro internacional de altos estudios agronómicos mediterráneos (editors) (2008) Evolución del consumo y de la alimentación. In Terramed: el futuro del sector agroalimentario en el mediterráneo, pp. 157-180. Madrid: Ministerio de Medio Ambiente y Medio Rural y Marino.

17. Slavin J (2004) Whole grains and human health. Nutr Res Rev 17, 99-110.

18. Tang L, Zirpoli GR, Guru K et al. (2008) Consumption of raw cruciferous vegetables is inversely associated with bladder cancer risk. Cancer Epidemiol Biomarkers Prev 17, 938-944.

19. Khoo HE, Prasad KN, Kong KW et al. (2001) Carotenoids and their isomers: color pigments in fruits and vegetables. Molecules 16, 1710-1738.

20. Ascherio A (2002) Epidemiological studies on dietary fats and coronary heart disease. Am J Med 113, Suppl. 9B, 9S-12S.

21. Casal S, Malheiro R \& Sendas A (2010) Olive oil stability under deep-frying conditions. Food Chem Toxicol $\mathbf{4 8}$, 2972-2979.

22. Bertuzzi M, Tavani A, Negri E et al. (2002) Olive oil consumption and risk of non-fatal myocardial infarction in Italy. Int J Epidemiol 31, 1274-1277.

23. Pérez-Jiménez F, Lista JD, Pérez-Martínez P et al. (2006) Olive oil and haemostasis: a review on its healthy effects. Public Health Nutr 9, 1083-1088.

24. La Vecchia C (2009) Association between Mediterranean dietary patterns and cancer risk: review. Nutr Rev 67, Suppl. 1, S126-S129.

25. Castañer O, Fitó M, López-Sabater MC et al. (2011) The effect of olive oil polyphenols on antibodies against oxidized LDL. A randomized clinical trial. Clin Nutr (Epublication ahead of print version).

26. Pelucchi C, Bosetti C, Negri E et al. (2011) Olive oil and cancer risk: an update of epidemiological findings through 2010. Curr Pharm Des 17, 805-812. 
27. Corona G, Spencer JP \& Dessì MA (2009) Extra virgin olive oil phenolics: absorption, metabolism, and biological activities in the GI tract: review. Toxicol Ind Health 25, 285-293.

28. Sabaté J, Ros E \& Salas-Salvadó J (2006) Nuts: nutrition and health outcomes. Preface. Br J Nutr 96, Suppl. 2, S1- S2.

29. World Health Organization (2004) Global Strategy on Diet, Physical Activity and Health. The Fifty-seventh World Health Assembly, Resolution WHA57. Geneva: WHO; available at http://www.who.int/gb/ebwha/pdf_files/WHA57/ A57_R17-en.pdf

30. Mink PJ, Scrafford CG, Barraj LM et al. (2007) Flavonoid intake and cardiovascular disease mortality: a prospective study in postmenopausal women. Am J Clin Nutr 85 , 895-909.

31. Pasten C \& Grenett H (2006) Wine, fibrinolysis and health. Rev Med Chil 134, 1040-1048.

32. Vilavalur R, Otani H, Singal PK et al. (2006) Significance of wine and resveratrol in cardiovascular disease: French paradox revisited. Exp Clin Cardiol 11, 217-225.

33. Kris-Etherton PM, Harris WS \& Appel LJ (2002) American Heart Association. Nutrition Committee. Fish consumption, fish oil, omega-3 fatty acids, and cardiovascular disease. Circulation 106, 2747-2757.

34. Simopoulos AP (2006) Evolutionary aspects of diet, the omega-6/omega 3-ratio and genetic variation. Biomed Pharmacother 60, 502-507.

35. Micha R, Wallace SK \& Mozaffarian D (2010) Red and processed meat consumption and risk of incident coronary heart disease, stroke, and diabetes mellitus: a systematic review and meta-analysis. Circulation 121, 2271-2283.

36. World Health Organization (2003) Diet, Nutrition and the Prevention of Chronic Diseases. Joint WHO/FAO Expert Consultation. WHO Technical Report Series no. 916. Geneva: WHO.

37. Rochfort S \& Panozzo J (2007) Phytochemicals for health, the role of pulses. J Agric Food Chem 55, 7981-7994.

38. Bazzano L, He J, Ogden L et al. (2001) Legume consumption and risk of coronary heart disease in US men and women: NHANES I Epidemiologic Follow-up Study. Arch Int Med 161, 2573-2578.

39. Mozaffarian D, Hao T, Rimm EB et al. (2011) Changes in diet and lifestyle and long-term weight gain in women and men. New Engl J Med 364, 2392-2404.

40. Willett W, Manson J \& Liu S (2002) Glycemic index, glycemic load, and risk of type 2 diabetes. Am J Clin Nutr 76, Suppl. 1, 274S-280S.

41. Medina FX (1996) Dieta y comportamientos alimentarios en el contexto mediterráneo. In La alimentación mediterránea. Historia, cultura, nutrición, p. 42 [FX Medina, editor]. Barcelona: Icaria.

42. De Garine I (1993) La dieta mediterránea en el conjunto de los sistemas alimentarios. In Antropología de la alimentación: ensayos sobre la dieta mediterránea, pp. 9-26 [I González Turmo and P Romero Solís, editors]. Sevilla: Junta de Andalucía, Fundación Machado.

43. Thompson J, Boddy K, Stein K et al. (2011) Does participating in physical activity in outdoor natural environments have a greater effect on physical and mental wellbeing than physical activity indoors? A systematic review. Environ Sci Technol $\mathbf{4 5}$, 1761-1772.

44. Ficca G, Axelsson J, Mollicone DJ et al. (2010) Naps, cognition and performance. Sleep Med Rev 14, 249-258.

45. Sizer F \& Whitney E (2000) Food Safety and Food technology. In Nutrition concepts and controversies, pp. 507-545 [A Williams, J Wood and C Winter, editors]. Belmont: Wadsworth, Thomson Learning.

46. Harvard Medical School, Center for Health and the Global Environment (2010) Healthy and sustainable food. http://chge.med.harvard.edu/programs/food/nutrition.html (accessed May 2011).

47. Serra-Majem L (2010) Nutrición comunitaria y sostenibilidad: concepto y evidencias. Revista Española de Nutrición Comunitaria 16, 35-40.

48. Gussow JD (1995) Mediterranean diets: are they environmentally responsible? Am J Clin Nutr 61, Suppl. 6, 1383S-1389S.

49. Stehfest E, Bouwman L, Van Vuuren DP et al. (2009) Climate benefits of changing diet. Climatic Change 95, 83-102.

50. Food and Agricultural Organization (2010) Biodiversity in Sustainable Diets. Technical Workshop Report. Rome: FAO; available at http://www.fao.org/ag/humannutrition/ 24994-064a7cf9328fbe211363424ba7796919a.pdf

51. Gussow JD \& Clancy KL (1986) Dietary guidelines for sustainability. J Nutr Educ 18, 1-5.

52. Goldman IL, Kader AA \& Heintz C (1999) Influence of production, handling, and storage on Phytonutrient content of food. Nutr Rev 57, 9 Pt 2, S46-S52.

53. Myers N, Mittermeier RA, Mittermeier CG et al. (2000) Biodiversity hotspots for conservation priorities. Nature $\mathbf{2 4}$, 853-858.

54. Trichopoulou A, Vasilopoulou E, Hollman P et al. (2000) Nutritional composition and flavonoid content of edible wild greens and green pies: a potential rich source of antioxidant nutrients in the Mediterranean diet. Food Chem 70, 319-323.

55. Johns T \& Sthapit BR (2004) Biocultural diversity in the sustainability of developing-country food systems. Food Nutr Bull 25, 143-155.

56. Dangour AD, Dodhia SK, Hayter A et al. (2009) Nutritional quality of organic foods: a systematic review. Am J Clin Nutr 90, 680-685.

57. Food Standards Agency (2009) Comparison of Composition (Nutrients and Other Substances) of Organically and Conventionally Produced Foodstuffs: A Systematic Review of Available Literature. London, UK: FSA; available at http://www.food.gov.uk

58. Lairon D (2010) Nutritional quality and safety of organic food. A review. Agron Sustain Dev 30, 33-41.

59. Carlsson-Kanyama A \& González AD (2009) Potential contributions of food consumption patterns to climate change. Am J Clin Nutr 89, Suppl. 5, 1704S-1709S.

60. Horrigan L, Lawrence RS \& Walker P (2002) How sustainable agriculture can address the environmental and human health harms of industrial agriculture. Environ Health Perspect 110, 445-456.

61. Burlingame B \& Dernini S (2011) Sustainable diets: the Mediterranean diet as an example. Public Health Nutr 14 Suppl. 1, 2285-2287. 